\title{
Pediatric Palliative Screening Scale (PaPaS Scale) in pediatric cancer patients: a qualitative study approach
}

\author{
Cecilia Ugaz ${ }^{1}$, Irma Ortiz ${ }^{1}$, Georgina Soto $^{2}$, Roxana Morales ${ }^{1}$, and Liliana Vasquez ${ }^{3}$ \\ ${ }^{1}$ Instituto Nacional de Enfermedades Neoplasicas \\ ${ }^{2}$ Instituto Nacional de Enfermedades Neoplásicas \\ ${ }^{3}$ PAHO Perú
}

July 9, 2021

\section{Hosted file}

Paper PaPas Ugaz 1.docx available at https://authorea.com/users/330952/articles/529798pediatric-palliative-screening-scale-papas-scale-in-pediatric-cancer-patients-aqualitative-study-approach 